\title{
An app for supporting older people receiving home care - usage, aspects of health and health literacy: a quasi- experimental study
}

Carina Göransson ${ }^{1,2^{*}}$ (D, Yvonne Wengström ${ }^{3,4}$, Maria Hälleberg-Nyman ${ }^{1}$, Ann Langius-Eklöf ${ }^{4}$, Kristina Ziegert $^{2}$ and Karin Blomberg ${ }^{1}$

\begin{abstract}
Background: During the last decade, there has been an increase in studies describing use of mHealth, using smartphones with apps, in the healthcare system by a variety of populations. Despite this, few interventions including apps are targeting older people receiving home care. Developing mobile technology to its full potential of being interactive in real time remains a challenge. The current study is part of a larger project for identifying and managing health concerns via an app by using real-time data. The aim of the study was to describe older people's usage of an app and to evaluate the impact of usage on aspects of health and health literacy over time.

Methods: A quasi-experimental design was employed. Seventeen older people self-reported health concerns via Interaktor twice a week for 3-months and answered questionnaires at baseline, the end of the intervention and at a 6-month follow-up. Logged data on app usage and data on Sense of Coherence, Health Index, Nutrition Form for the Elderly, Geriatric Depression Scale-20, Swedish Communicative and Critical Health Literacy and Swedish Functional Health Literacy were collected and analysed using descriptive and non-parametric inferential statistics.

Results: The median usage of the app as intended was 96\%. Pain was one of the most reported health concerns and was also the health concern that triggered an alert $(n=33)$. The older people's communicative and critical health literacy improved significantly over time. Regarding the scores of Sense of Coherence, Health Index, Nutritional Form for the Elderly, Geriatric Depression Scale-20 and Swedish Functional Health Literacy scale, there were no significant differences over time.

Conclusions: The high app usage showed that an app may be a suitable tool for some older people living alone and receiving home care. The results indicate that the usage of Interaktor can support older people by significantly improving their communicative and critical health literacy. Aspects of health were not shown to be affected by the usage of the app. Further research with larger sample is needed for evaluation the effect on health literacy, and which aspects of health of importance to support by an app.
\end{abstract}

Keywords: Alert, App, Health, Health concerns, Home care, mHealth, Older people, Self-report, Usage

\footnotetext{
* Correspondence: carina.goransson@hh.se

${ }^{1}$ Faculty of Medicine and Health, School of Health Sciences, Örebro University, 70182 Örebro, Sweden

${ }^{2}$ School of Health and Welfare, Halmstad University, 30218 Halmstad, Sweden

Full list of author information is available at the end of the article
}

C C The Author(s). 2020 Open Access This article is licensed under a Creative Commons Attribution 4.0 International License, which permits use, sharing, adaptation, distribution and reproduction in any medium or format, as long as you give appropriate credit to the original author(s) and the source, provide a link to the Creative Commons licence, and indicate if changes were made. The images or other third party material in this article are included in the article's Creative Commons licence, unless indicated otherwise in a credit line to the material. If material is not included in the article's Creative Commons licence and your intended use is not permitted by statutory regulation or exceeds the permitted use, you will need to obtain permission directly from the copyright holder. To view a copy of this licence, visit http://creativecommons.org/licenses/by/4.0/. The Creative Commons Public Domain Dedication waiver (http://creativecommons.org/publicdomain/zero/1.0/) applies to the data made available in this article, unless otherwise stated in a credit line to the data. 


\section{Background}

Older people have an increasing interest in using the internet to seek health-related information [1]. Even so, it has been concluded that they are less prone to seek health-related information on the internet than younger people, and when older people have several health problems the information seeking decreases $[2,3]$. Understanding health-related information requires a certain level of health literacy, which is defined by the World Health Organization as the ability to "gain access to, understand and use information in ways which promote and maintain good health" [4]. It has been proposed that poor health literacy in the oldest old people can be a barrier both to seeking health information and to adopting mHealth [5].

MHealth has been described as the use of mobile technology to transfer health data in healthcare services as well as to seek and receive health information in order to improve health outcomes [6]. The use of mobile technology, such as computers, smartphones and tablets with integrated apps for collecting data and monitoring different conditions, is growing in the healthcare system [7]. Studies have focused on self-reporting and monitoring health problems related to specific chronic conditions such as diabetes or chronic heart failure $[8,9]$, and have shown significantly improved clinical outcomes, for example a decrease in HbA1c levels and blood pressure [10]. Even in those studies that focus on people's selfreporting of health problems in apps, interactive components with healthcare professionals are rare [10]. To alleviate health problems an automatic feedback in the apps can be included, for instance in the form of selfcare advice to the users [8].

In Sweden, an increasing proportion of older people with health problems are cared for in their own homes [11]. This puts demands on the healthcare system to develop innovative ways of coordinating care as well as to improve health literacy for older people so that they can utilize mHealth [12]. Studies including older people receiving home care and using mHealth interventions to alleviate health problems are limited [13]. Therefore, it is of importance to evaluate, and support, the use of mHealth to identify and enable early detection of health problems in older people.

To meet this need, our research group developed an interactive app, Interaktor, based on the theoretical framework of participation and person-centered care [14-16]. Patient participation is described as the person's involvement in health and care, and having knowledge, as well as interaction with healthcare professionals [14]. Furthermore, person-centred participation is based on the person's values and preferences, knowledge building and perceived taking control of their care [15]. Person-centered care also includes the person's perspective of the care and the interaction as a partnership between the person receiving care and the healthcare professionals [16]. These concepts all emphasize the person's values and knowledge, as well as strategies for taking an active role in their own health, and to perform activities for their health and self-care [14-16].

The app aims to support self-management of health concerns and has been developed for different populations [17-19]. The platform for Interaktor includes: (1) a component for assessment of the occurrence, frequency and distress level of health concerns; (2) connection to a monitoring web interface for healthcare professionals and logged data storage on a secure server; (3) a risk assessment model that sends alerts via short message service (SMS) to nurses; (4) continuous access to evidence-based self-care advice and links to relevant websites; and (5) graphs to view the history of reporting. The first version developed for older people receiving home care has been shown to be acceptable and userfriendly [20].

The aim of the study was to describe older people's usage of an app and to evaluate the impact of the usage on aspects of health and health literacy over time.

\section{Methods \\ Design}

The design of this study was guided by the framework of The Medical Research Council's for developing and evaluating complex interventions [21]. The framework's three steps are: (1) define and understand the problem and the context; (2) develop the intervention; and (3) develop and optimize the evaluation. This quasiexperimental study is a part of the development and optimization phase that focuses on the outcomes of the intervention.

\section{Participants}

The study was conducted in two municipalities in southwestern Sweden, one in rural area (site A) and one in an urban area (site B). The municipalities in Sweden are responsible by the laws set forth by the Health and Medical Services Act and the Social Services Act to offer home care services. These services are performed by different professions such as registered nurses working as homecare nurses $[22,23]$. The homecare nurses identified eligible older people meeting the inclusion criteria: $\geq 65$ years old, living in their own home, receiving home care, and having no cognitive impairment. In total 76 older people were identified and informed about the study by their homecare nurse, of those 76 older people a few were informed by a researcher during a meeting in one of the municipality's centres for older people. Fiftyone submitted contact information, and were contacted by researcher and 19 chose at that point not to 
participate. The remaining 32 older people received information regarding the study and an introduction to the app and smartphone or tablet. The final sample consisted of 24 older people who used either a tablet (at site A, $n=15$ ) or a smartphone (at site $B, n=9$ ). Five older people dropped out, and two participants deceased, which left 17 participants who completed the study (Fig. 1). A more detailed description of the recruitment process for the participants has been published elsewhere [24, 25].

The Interaktor app for older people receiving home care The contents with different functions in the interactive app has been described in detail elsewhere [24]. In short, the 13 included health concerns were based on a literature review and interviews with older people and healthcare professionals [26]. The health concerns were assessed using standardized questions that included occurrence, frequency and distress level of the particular health concern $[27,28]$, which were programmed to trigger alerts based on algorithms. The algorithms were based on the older people's self-reports of frequency and/or distress levels of the health concerns [24]. There were two kinds of alerts, yellow and red, depending on the severity of the health concerns and were sent instantly and automatically to the homecare nurses' mobile phones. The homecare nurses contacted the older people in regard to their alerts and afterwards entered standardized notes into the system about the action taken, for example "contacted the patient", "home visit" or "contact with physician". The app includes access to self-care advice targeting older people and with links for further reading [29, 30]. Finally, the app allowed the older people to view the history of their reported health concerns in graphs over time. A more detailed description of the development of the contents in the Interaktor has been published elsewhere [24, 25].

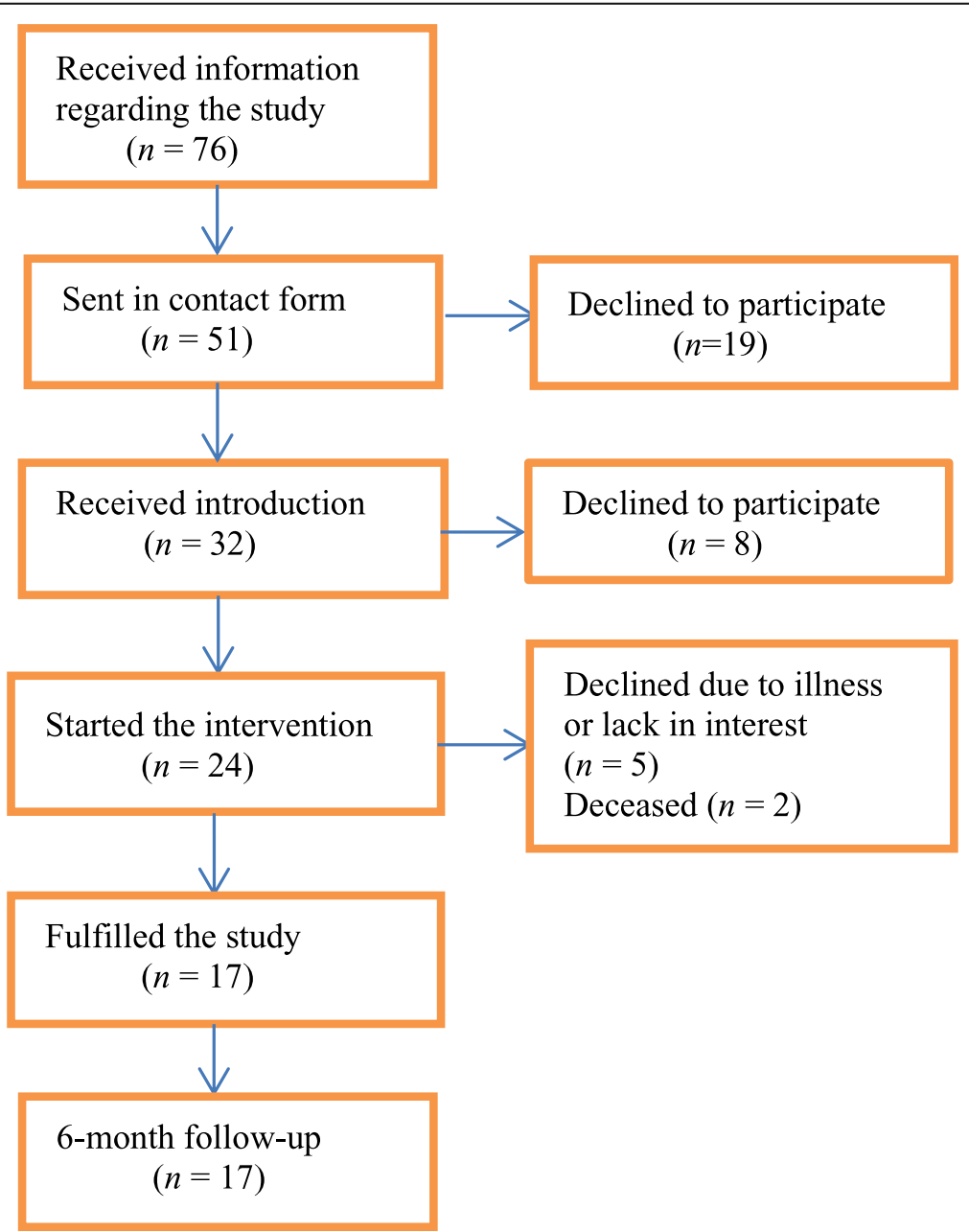

Fig. 1 Flow chart over older persons participating in the intervention 


\section{Procedure}

The procedure of the intervention has been described in detail elsewhere [25]. The older people were provided with a smartphone or tablet on which Interaktor had been installed. They also received a code to log into Interaktor, as well as an identification number. They received written information from the researcher including screenshots of how to use the different functions in the app. The older people were instructed to submit a selfreport twice a week on specific weekdays during the 3month intervention, in total 26 times, and more often if needed. This was considered appropriate based on a previous study [20]. The homecare nurses were able to view the reported health concerns and alerts on the web interface.

\section{Data collection}

\section{Logged data}

Data extracted from the database of logged data included: (1) the total number of participants' self-reports; (2) the number of self-reports per health concern; (3) the occurrence, frequency and distress levels of health concerns; (4) the alerts generated; and (5) homecare nurses' notes of actions based on generated alerts from the web interface.

\section{Questionnaires}

The older people received paper questionnaires at baseline, at the end of the intervention and at the 6month follow-up. At baseline, the participants were given the questionnaires before the introduction of the smartphone/tablet and Interaktor. Some participants received support from the researcher who posed the questions verbally and filled out the questionnaires for them. After the intervention, the older people received the questionnaires when the smartphone/tablet was collected. At the 6-month follow-up the older people received the questionnaires by post and returned it in a prepaid envelope.

\section{Aspects of health}

The Sense of Coherence (SOC) scale measures how people cope, and also their general view of life, in dimensions of meaningfulness, manageability and comprehensibility [31]. It includes 13 items and respondents indicate agreement or disagreement on a 7-point scale, with two anchoring responses tailored to the content of each item. Five of the items are negatively stated and reverse-scored when calculating the total score. The total score range is 13-91; and a higher total score indicates better perceived health in general. The SOC scale has been psychometrically tested and has been found to be reliable and valid in different settings and in a variety of populations $[31,32]$. The Health Index $(\mathrm{HI})$ is a generic instrument for perceived general health [33]. It includes nine items and four response alternatives ranging from "very poor" to "very good". The total score is minimum 9 and maximum 36. A higher score indicates better perceived health. The HI has shown to be reliable and valid both in hospital settings and in a population sample [33, 34]. The Nutritional Form for the Elderly (NUFFE) was used for screening the risk of undernutrition in older people [35]. This instrument comprises 15 items related to a person's nutritional situation and has three response alternatives. The score ranges from 0 to 30 . A score of $0-5$ indicates that there is no risk of undernutrition, while a score of 6-12 indicates a moderate risk, and a score of $\geq 13$ indicates a high risk of undernutrition. The NUFFE has shown reliable properties and has been validated in older people and rehabilitation settings [36]. The Geriatric Depression Scale (GDS)-20 is a screening tool for depression in older people [37]. It contains 20 dichotomous items (yes/no). A total score of $>5$ indicates suspected depression. The GDS-20 has been described as reliable and valid in older people and for use in primary care centres [37].

\section{Health literacy}

The Swedish Functional Health Literacy (S-FHL) scale measures ability to read and understand health information [38]. It comprises five items with four response alternatives ranging from "never" to "often" [39]. The Swedish Communicative \& Critical Health Literacy (S-C \& $\mathrm{C} \mathrm{HL}$ ) scale is used to assess the skill to extract information and apply it [40]. It includes five items with five response alternatives, from "totally disagree" to "totally agree". In both scales the score is calculated by collapsing the response alternatives into three: 1, 100 and 1000. The total score was calculated for each person and scores were categorized into three groups: sufficient < 100, problematic 100-1000, and inadequate > 1000 [41]. The S-FHL and S-C \& C HL scales have been found to be reliable and valid $[38,40]$.

\section{Data analysis}

Logged data were analysed with descriptive statistics. The older people's usage of Interaktor for health reporting was calculated as the number of days an older person submitted a report, divided by the number of days that person was intended to submit a report, and presented as a percentage. The logged data of the selfreported health concerns were organized by frequency, where 1 =almost never; 2 = sometimes; 3 =often; and 4 = almost always, and also by how distressing the health concern was, where $1=$ not at all; $2=$ a little; $3=$ pretty much; and $4=$ very much. 
In the analysis of the questionnaires, non-parametric tests were used [42]. To analyse differences over time the Friedman test for ordinal-level data, and Cochran's $\mathrm{Q}$ test for nominal data were used. Differences between the three assessment points (baseline, end of the intervention, and 6-month follow-up) were analysed using the Wilcoxon signed-rank test for ordinal-level and McNemar's test for nominal data [42]. All analyses were performed using IBM SPSS version 24.0. $P$-values (twotailed) $<0.05$ were considered statistically significant.

\section{Results}

The mean age was 86 years (range 70-101), and eleven women and six men were included. Nearly all participants lived on their own. Fourteen participants had adult children who did not live with them. The most common medical diagnosis was cardiovascular diseases followed by musculoskeletal disease (Table 1).

\section{The usage of the app}

The logged data showed that the median usage of Interaktor was 96\% (range 3-100\%). For the group using a smartphone, the median was $83 \%$ (range $62-100 \%$ ) and for tablet users, it was $100 \%$ (range 3-100\%). The total number of self-reports submitted by the older people $(n=17)$ during the intervention was 383 , and these 383 self-reports contained altogether 1253 health concerns. The most common self-reported health concerns were difficulties performing personal daily activities and difficulties performing social activities outside the home, followed by pain, fatigue, insomnia/sleeping problems, dizziness, worry, sadness, diarrhoea, constipation, loss of

Table 1 Participants' sociodemographic and medical characteristics

\begin{tabular}{ll}
\hline Variables & $\mathbf{( N = \mathbf { 1 7 } )}$ \\
\hline Age, yrs., mean (SD) & $86(6.5)$ \\
Female, $n$ (\%) & $11(64.7)$ \\
Marital status, $\boldsymbol{n}$ (\%) & $1(5.8)$ \\
$\quad$ Married/living with partner & $16(94.1)$ \\
$\quad$ Living alone & \\
Education, $\boldsymbol{n}$ (\%) & $11(64.7)$ \\
$\quad$ Junior compulsory & $1(5.8)$ \\
Senior high school & $4(23.5)$ \\
College/university & $1(5.8)$ \\
Other education & \\
Medical diagnosis, $\boldsymbol{n}$ (\%) & $15(88.2)$ \\
Cardiovascular & $9(52.9)$ \\
Musculoskeletal & $4(23.5)$ \\
\hline Respiratory &
\end{tabular}

$S D$ standard deviation appetite, difficulty eating, and fever (Table 2). The frequency and distress levels varied for the included health concerns. All four levels of frequency and distress were reported (for the distribution of answers, see Table 2).

Of the self-reported health concerns, 79 generated alerts to the homecare nurses, 74 were yellow (less severe) and five were red alerts (severe). The most common self-reported health concern that triggered alerts was pain (yellow, $n=33$ ) (Table 3). The total alerts (yellow and red) were generated by 14 of the participants, with a median of five alerts (minimum one alert, maximum 16) during the time of using Interaktor.

Of the 74 yellow alerts, 35 led to the homecare nurses taking actions and making notes (Table 4). The actions taken by the homecare nurses when they received an alert included home visits $(n=10)$ and contact with the patient $(n=6)$. When the first alert came in, the homecare nurses made the most notes, but when subsequent alerts came in for the same health concern, they either noted "no action" or stopped making notes. In 39 alerts, no comments were noted. In 19 of these, the alerts were sent by the same two older people regarding the same health concern, pain.

\section{Aspects of health and health literacy}

The statistical analysis did not show any significant changes over time for the included instruments measuring aspects of health (Table 5). The older people's SOC scores showed a small, but not significant, increase at the end of the intervention compared with baseline and at 6-month follow-up. The participants' general health was unchanged from baseline to the end of the intervention and the 6-month follow-up. The older people had a moderate risk of undernutrition, from baseline to 6month follow-up. The results indicated no suspected depression at any of the three measurement points. The older people's functional health literacy (Swedish FHL Scale) did not differ significantly between baseline, the end of the intervention and the 6-month follow-up. Their communicative and critical health literacy, indicated by the Swedish C \& C HL Scale, had improved by the 6-month follow-up compared with both baseline $(p=0.02)$ and the end of the intervention $(p=0.02)$ (Table 6).

\section{Discussion}

The Interaktor usage seems to have improved the older people's health literacy, concerning their ability to extract health information and apply it, as seen at the 6month follow-up. This result is interesting, as health literacy is known to decline with old age [5], and low health literacy has been described elsewhere as an obstacle to older people seeking for health information and using mHealth $[3,43]$. It has also been reported that old 
Table 2 Participants' ( $N=17)$ self-reported health concerns, by occurrence, frequency and distress level

\begin{tabular}{|c|c|c|c|c|c|}
\hline \multirow[t]{2}{*}{ Health concerns } & \multirow{2}{*}{$\begin{array}{l}\text { Occurrence } \\
n(\%)\end{array}$} & \multicolumn{2}{|l|}{ Frequency } & \multicolumn{2}{|l|}{ Distress } \\
\hline & & Median $\left(Q_{1}-Q_{3}\right)$ & Range & Median $\left(Q_{1}-Q_{3}\right)$ & Range \\
\hline Difficulties performing personal daily activities $(n=17)$ & $262(20.9)$ & $3(2-3)$ & $1-4$ & $2(2-3)$ & $1-4$ \\
\hline Difficulties performing social activities outside the home $(n=17)$ & $252(20.1)$ & $3(2-3)$ & $1-4$ & $2(2-3)$ & $1-4$ \\
\hline Pain $(n=13)$ & $221(17.6)$ & $3(3-4)$ & $1-4$ & $3(2-3)$ & $1-4$ \\
\hline Fatigue $(n=14)$ & $190(15.1)$ & $3(2-4)$ & $1-4$ & $2.5(2-3)$ & $1-4$ \\
\hline Insomnia/sleeping difficulties $(n=11)$ & $87(6.9)$ & $3(2-3)$ & $1-4$ & $2(2-3)$ & $1-4$ \\
\hline Dizziness $(n=8)$ & $71(5.6)$ & $2(2-3)$ & $1-4$ & $2(2-3)$ & $1-4$ \\
\hline Worry $(n=9)$ & $50(3.9)$ & $2(2-3)$ & $1-4$ & $2(2)$ & $1-4$ \\
\hline Sadness $(n=11)$ & $49(3.9)$ & $2(2)$ & $1-4$ & $2(2)$ & $1-4$ \\
\hline Diarrhoea $(n=7)$ & $34(2.7)$ & $2(2-3)$ & $1-4$ & $2(2)$ & $1-4$ \\
\hline Constipation $(n=4)$ & $14(1.1)$ & $2(2)$ & $1-4$ & $2(2)$ & $1-4$ \\
\hline Loss of appetite $(n=6)$ & $12(0.9)$ & $3(2-4)$ & $1-4$ & $2(2)$ & $1-4$ \\
\hline Difficulties eating $(n=5)$ & $6(0.4)$ & $1(1-2)$ & $1-4$ & $1.5(1-2)$ & $1-4$ \\
\hline Fever $(n=4)$ & $5(0.4)$ & $2(1-2)$ & $1-4$ & $2(1-2)$ & $1-4$ \\
\hline Total & 1253 & & & & \\
\hline
\end{tabular}

Frequency: 1 = almost never; $2=$ sometimes; $3=$ often; and $4=$ almost always. Distress levels: $1=$ not at all; $2=a$ little; $3=$ pretty much; $4=$ very much. $Q_{1}=$ first quartile; $\mathrm{Q}_{3}=$ third quartile

age and having several medical conditions can have a negative impact on using technology to seek health information [2]. Using an app can confirm older people's prior knowledge and increase their self-confidence in self-care [24]. The improvement in health literacy for the older people in the current study may be due to the fact that the included information and links to websites were specifically targeted to an older population [30]. When information is adapted to older people's situation and interests, the likelihood is that it will be used [44]. Another explanation for the improved health literacy could be the instant access to health information in a new way that Interaktor provided. This may have

Table 3 Distribution and category of alerts linked to self-reports by the participants $(N=14)$ during the intervention

\begin{tabular}{lll}
\hline Health concerns & $\begin{array}{l}\text { Yellow alerts } \\
\boldsymbol{n}(\%)\end{array}$ & $\begin{array}{l}\text { Red alerts } \\
\boldsymbol{n}(\%)\end{array}$ \\
\hline Pain $(n=9)$ & $33(44.5)$ & $3(60.0)$ \\
Dizziness $(n=4)$ & $20(27.0)$ & $2(40.0)$ \\
Diarrhoea $(n=3)$ & $14(18.9)$ & \\
Fever, 3 days $(n=2)$ & $2(2.7)$ & \\
Sadness, 2 days $(n=1)$ & $1(1.3)$ & \\
Difficulties eating $(n=1)$ & $1(1.3)$ & \\
Fever $(n=1)$ & $1(1.3)$ & $\mathbf{5}$ \\
Constipation $(n=1)$ & $1(1.3)$ & $1(1.3)$ \\
Diarrhoea and fever $(n=1)$ & $\mathbf{7 4}$ & \\
Total alerts &
\end{tabular}

Yellow alert: the homecare nurse contacted the participant within $24 \mathrm{~h}$ Red alert: the homecare nurse contacted the participant on the same day stimulated the older people after completing the intervention to seek more health information and apply it. It has been reported that older people's health literacy can be stimulated by the use of mHealth [5].

The older people's aspects of health did not change during the 3 months that they used Interaktor. The short intervention time may have affected the possibility to improve aspects of health. It has been shown that specific health outcomes can be enhanced by self-reporting via smartphone; however, the intervention time varies between studies from 2 months to 1 year $[9,10]$, indicating that deciding what time period is the most suitable for accurate evaluation of health outcomes can be challenging. Another reason for the unchanged aspects of health in the current study may be the older people's advanced age, in comparison to participants in the aforementioned studies, most of whom were $<70$ years old [9, 10]. Studies targeting older people with chronic conditions using mHealth have shown that the impact on health can vary, demonstrating a range of impact from improvement to no effect $[5,8]$. However, to self-report on a regular basis can be a reminder of illness [45]. For the older people in the current study, this does not seem to have been the case, as the aspects of health remained unaffected. Therefore, it is important to further evaluate the Interaktor app in home care, in terms of which aspects of health are most important and can be supported by using an app.

The most health concerns self-reported by the older people were difficulties performing personal daily activities, difficulties performing social activities outside 
Table 4 Notes made by the homecare nurses when receiving alerts from the participants $(N=14)$

\begin{tabular}{lll}
\hline Notes & Yellow alerts, $\boldsymbol{n}$ & Red alerts, $\boldsymbol{n}$ \\
\hline Home visit & 10 \\
No action & 10 & 1 \\
Contacted the patient & 6 & 2 \\
Telephone contact & 4 \\
Booked visit with the patient & 1 \\
Tried to reach the patient - no answer & 1 \\
Patient had contact with the physiotherapist & 1 \\
Information received - no action taken & 1 \\
Is sorted out; nothing new & 1 \\
No action; alert probably due to participant pressing the wrong key & \\
No notes made & 39 \\
Total & $\mathbf{7 4}$ \\
\hline
\end{tabular}

Yellow alert: the homecare nurse contacted the participant within $24 \mathrm{~h}$

Red alert: the homecare nurse contacted the participant on the same day

home and pain. The reason for the high frequencies of difficulties performing activities may be the high median age (86 years) of the older people included here, as it is well known that physical ability in daily life becomes more of an issue with advanced age [46]. Compared with the past, today more older people are living in their own home rather than in nursing homes, and receiving help with activities of daily living (ADLs) [47]. By giving these people the opportunity to self-report their health concerns via an app, the homecare nurses can detect any change in ADL function at an early stage and take relevant action. It is of importance to self-report difficulities performing personal activities and social activities with others, as physical ability and health are known to be interrelated [48].

Pain was likewise a highly self-reported health concern among the older people participating in the present study. This is in line with results from another study describing pain as a common health concern in older people [49], although it has also been stated that the prevalence of pain can vary among older people [50]. Another reason for the high self-reporting frequencies could be that the app gave the older people a new opportunity to communicate pain, as also described in our previous study [24]. This is important as it is concluded that insufficient assessment by healthcare professionals and communication regarding older people's pain can occur [50].

Pain was the health concern which triggered most alerts. The reason for this could be that the level for triggering alerts for pain was set too low. Once an older person's pain was well known to the homecare nurses and had been repeatedly reported at the same frequency and distress level, the nurses did not always write notes about actions taken. This may be so because the nurses were already aware of the level of the pain problem; or else it may have been due to their heavy workload, as described previously [24].

The older people's high app usage can be explained by our previous results, which describe the Interaktor as

Table 5 Comparison of the median scores for the included instruments at baseline, at the end of the intervention and at 6-month follow-up $(N=17)$

\begin{tabular}{|c|c|c|c|c|c|c|c|c|}
\hline \multirow[t]{2}{*}{ Instruments } & \multirow[t]{2}{*}{ Range } & \multirow[b]{2}{*}{ Baseline } & \multicolumn{2}{|l|}{ Median $\left(Q_{1}-Q_{3}\right)$} & \multirow[b]{2}{*}{$P$-value ${ }^{\mathrm{a}}$} & \multirow[b]{2}{*}{$P$-value ${ }^{b}$} & \multirow[b]{2}{*}{$P$-value ${ }^{c}$} & \multirow[b]{2}{*}{$P$-value ${ }^{\mathrm{d}}$} \\
\hline & & & End of intervention & 6-month follow-up & & & & \\
\hline SOC scale & $13-91$ & $63(59-70)^{\gamma}$ & $66(59.7-74.5)^{\beta}$ & $64(59-73)^{\pi}$ & $0.08^{\prime}$ & $0.75^{\prime}$ & $0.07^{\prime}$ & 0.11 \\
\hline $\mathrm{HI}$ & $9-36$ & $24(23-28.7)^{\beta}$ & $24.5(21.2-28)^{\beta}$ & $25(22-28)^{\pi}$ & $0.50^{\prime}$ & $0.06^{\prime}$ & $0.17^{\prime}$ & 0.33 \\
\hline NUFFE & $0-30$ & $6(4-9.5)^{\gamma}$ & $8(4.5-9.5)^{\gamma}$ & $7(5-9)^{\pi}$ & $0.30^{\prime}$ & $0.52^{\prime}$ & $0.13^{\prime}$ & 0.65 \\
\hline GDS & $0-20$ & $3(2.2-5.5)^{\varepsilon}$ & $5(2-9)^{\pi}$ & $5(4-8)^{\pi}$ & $0.12^{a}$ & $0.21^{a}$ & $1.00^{\alpha}$ & $0.15^{\infty}$ \\
\hline
\end{tabular}

GDS Geriatric Depression Scale, $H$ I Health Index, NUFFE Nutritional Form for the Elderly, SOC Sense of Coherence. $\mathrm{Q}_{1}=$ first quartile; $\mathrm{Q}_{3}=$ third quartile ${ }^{\mathrm{a}}$ Baseline vs end of the intervention; ${ }^{\mathrm{b}}$ Baseline vs 6-month follow-up; ${ }^{\mathrm{C}}$ End of the intervention vs 6-month follow-up; ${ }^{\mathrm{d}}$ Comparison over time the three assessments points

Wilcoxon signed rank test; Friedman's test; ${ }^{\infty}$ Cochran's Q-test; ${ }^{a}$ McNemar's test

${ }^{\gamma_{n}}=17 ;^{\beta} n=16 ;{ }^{\pi} n=15 ;{ }^{\varepsilon} n=12$ 
Table 6 The participants' ( $N=17)$ levels of health literacy at baseline, at the end of the intervention and at 6-month follow-up

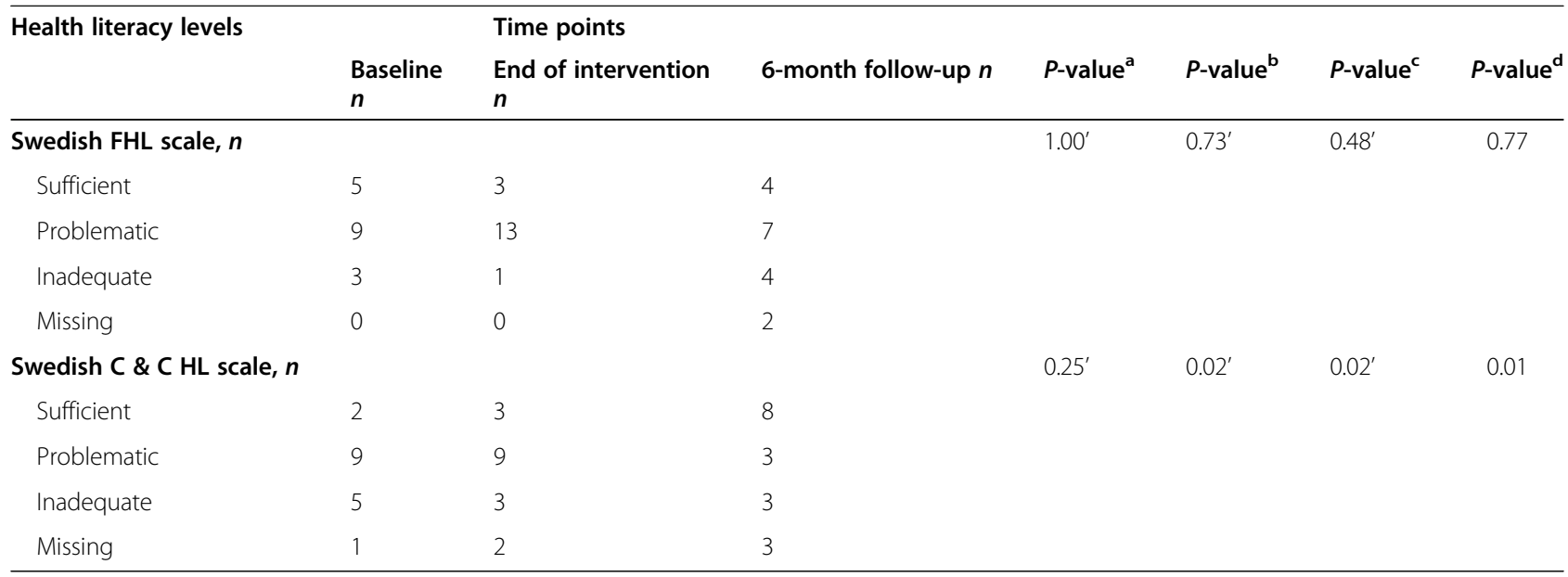

FHL Functional Health Literacy, C \& C HL Communicative and Critical Health Literacy

${ }^{\mathrm{a}}$ Baseline vs end of the intervention; ${ }^{\mathrm{b}}$ Baseline vs 6-month follow-up; ${ }^{\mathrm{C} E n d}$ of the intervention vs 6-month follow-up; ${ }^{\mathrm{d}}$ Comparison between all three assessment points

'Wilcoxon signed rank test; Friedman's test

easy to use as well as including health concerns that are relevant to older people [24]. Studies have shown lower frequency of app usage for people between 50 and 79 years old with different specific chronic conditions and in a variety of settings [51,52]. Other studies in different populations have shown high usage of Interaktor [1719]. The high usage in the current study may also reflect older people's interest in using new technology, which is in line with other studies pointing out that using new technology can prompt learning in older people [44]. Another reason for the high usage may be the trust the older people had in the homecare nurses when asked to participate in the study. This was described by the older people as making them feel modern and acknowledged as a valued person [24]. The homecare nurses may have played a role in inspiring the older people to use the app. It is stated that social influence impacts the use of new technology [53]. In the current study the majority of the older people lived on their own, and did not receive encouragement to use the app from a partner. Although the majority of the older people had adult children only a few mentioned the children's support when using the app [24]. In further studies it would be of interest to include family members' perspective and evaluate the impact of the older people's usage.

\section{Strengths and limitations}

The main limitation of this study was the small sample size. The homecare nurses identified more older people than were included as eligible for the study. However, not all invited people agreed to participate. This may indicate that some older people may have lacked confidence in using this new technology [43]. The older people who participated in this research had fewer health problems and medical diagnoses compared with older people receiving home care in general [24], which may have affected the results in terms of fewer reported health concerns, alerts and unchanged aspects of health. Furthermore, healthier older people are more likely to participate in studies compared with non-healthy people [54].

One strength of the study is the context of home care, since interventions using mHealth targeting older people in home care are limited [13]. More intervention studies are needed as the use of smartphones and tablets by older people is increasing [3].

The results should be generalized with caution [55]; nevertheless, they indicate outcomes of importance for studies including larger samples. Larger studies performed in patients with prostate cancer during radiotherapy and in patients after surgery of pancreatic cancer have shown that the use of the app Interaktor could contribute to alleviate the health problems $[18,19]$. However, it has been argued that to conduct studies with smaller samples within the field of mHealth is appropriate as the technology is developing rapidly [56]. To conduct small studies is also recommended in preparation for large-scale evaluation according to the framework for complex intervention [21]. Further studies with larger samples are needed to evaluate the impact of using Interaktor on aspects of older people's health and health literacy before implementation in home care.

\section{Conclusions}

This study indicates that an interactive app can be used as a tool for health concerns by some older people living alone and receiving home care. The older people's communicative and critical health literacy was improved by 
their usage of the app; but there was no significant improvement in aspects of health. The high usage of the app by the older people indicates the importance of including the increasing older population in the continued development of mHealth to be better integrated in home care for reporting health concerns in real time. Further research including larger samples and a longer intervention time is needed for evaluation of the effect of using applications of older people's health literacy, and which aspects of health are most important and can be supported by using an app.

\section{Abbreviations}

app: application; GDS-20: Geriatric Depression Scale-20; HI: Health Index mHealth: mobile health; NUFFE: Nutritional Form for the Elderly; S C \& C $\mathrm{HL}$ : Swedish Communicative and Critical Health Literacy Scale; S

FHL: Swedish Functional Health Literacy Scale; SMS: Short Message Service; SOC: Sense of Coherence

\section{Acknowledgements}

We would like to thank Irene Eriksson, RN, APN, PhD, at Skövde University, Skövde, Sweden, for collaboration in data collection, and Hansi Hinci, lecturer at Halmstad University, Halmstad, Sweden, for statistical advice.

\section{Authors' contributions}

$C G, Y W, M-N, A L-E, K Z$ and $K B$ authors were involved in the conception and design of the study, interpreted data and provided critical input and advice. CG performed data collection and was responsible for the analysis. CG, YW, $M-N, A L-E, K Z$ and KB wrote and critically revised the manuscript. The final version of the manuscript has been approved by all, CG, YW, M-N, AL-E, KZ and $K B$, authors.

\section{Funding}

The first author received internal funding from the School of Health and Welfare, Halmstad University, and the School of Health Sciences, Örebro University during data collection and analysis and preparation of the manuscript. The work was supported by a grant from the Swedish Research Council during data analysis and preparation of the manuscript. The founders had no role in study design, data collection and analysis, or preparation of the manuscript. We would like to thank Karolinska Institutet and the Swedish Research Council for supporting this study.

Open access funding provided by Halmstad University.

\section{Availability of data and materials}

The dataset used and analysed during the current study is available from the corresponding author upon reasonable request.

\section{Ethics approval and consent to participate}

The study was approved by the Regional Ethical Review Board at Uppsala University, Sweden (reg. no. 2012/357). All participants received information about the study and gave written informed consent.

\section{Consent for publication}

Not applicable.

\section{Competing interests}

The authors declare that they have no competing interests.

\section{Author details}

${ }^{1}$ Faculty of Medicine and Health, School of Health Sciences, Örebro University, 70182 Örebro, Sweden. ${ }^{2}$ School of Health and Welfare, Halmstad University, 30218 Halmstad, Sweden. ${ }^{3}$ Theme Cancer, Karolinska University Hospital, 14186 Stockholm, Sweden. ${ }^{4}$ Department of Neurobiology, Care Sciences and Society, Division of Nursing, Karolinska, Institutet, 17177 Stockholm, Sweden.
Received: 14 May 2020 Accepted: 3 September 2020

Published online: 15 September 2020

\section{References}

1. Vroman KG, Arthanat S, Lysack C. "Who over 65 is online?" Older adults' dispositions toward information communication technology. Comput Human Behav. 2015;43:156-66. https://doi.org/10.1016/j.chb.2014.10.018

2. Zhang Y, Lauche R, Sibbritt D, Olaniran B, Cook R, Adams J. Comparison of health information technology use between american adults with and without chronic health conditions: findings from the national health interview survey 2012. J Med Internet Res. 2017;19(10):e335. https://doi.org/ 10.2196/jmir.6989

3. Oh YS, Choi EY, Kim YS. Predictors of smartphone uses for health information seeking in the Korean elderly. Social Work in Public Health. 2018:33(1):43-54. https://doi.org/10.1080/19371918.2017.1391150.

4. World Health Organization. Health literacy The mandate for health literacy: World Health Organisation; 2016. Available from: https://www.who.int/ healthpromotion/conferences/9gchp/health-literacy/en/. Accessed 12 Dec 2018.

5. Kruse CS, Mileski M, Moreno J. Mobile health solutions for the aging population: a systematic narrative analysis. J Telemed Telecare. 2017;23(4): 439-51. https://doi.org/10.1177/1357633X16649790.

6. Cameron JD, Ramaprasad A, Syn T. An ontology of and roadmap for mHealth research. Int J Med Inform. 2017;100:16-25. https://doi.org/10.1016/ j.ijmedinf.2017.01.007.

7. World Health Organization. From Innovation to Implementation: eHealth in the WHO European Region Copenhagen. Denmark: WHO Regional Office for Europe: World Health Organization; 2016.

8. Kim BY, Lee J. Smart devices for older adults managing chronic disease: a scoping review. JMIR mHealth and uHealth. 2017;5(5):e69. https://doi.org/10. 2196/mhealth.7141.

9. Wang J, Wang Y, Wei C, Yao N, Yuan A, Shan Y, et al. Smartphone interventions for long-term health management of chronic diseases: an integrative review. Telemedicine and e-Health. 2014;20(6):570-83. https:// doi.org/10.1089/tmj.2013.0243.

10. Whitehead $L$, Seaton $P$. The effectiveness of self-management mobile phone and tablet apps in long-term condition management: a systematic review. J Med Internet Res. 2016;18(5):e97. https://doi.org/10.2196/jmir.4883.

11. Sund Levander M, Milberg A, Rodhe N, Tingström P, Grodzinsky E. Differences in predictors of 5-year survival over a 10-year period in two cohorts of elderly nursing home residents in Sweden. Scand J Caring Sci. 2016;30(4):714-20. https://doi.org/10.1111/scs.12284.

12. Rechel B, Grundy E, Robine J-M, Cylus J, Mackenbach JP, Knai C, et al. Ageing in the European union. Lancet. 2013;381 (9874):1312-22. https://doi. org/10.1016/S0140-6736(12)62087-X.

13. Matthew-Maich N, Harris L, Ploeg J, Markle-Reid M, Valaitis R, Ibrahim S, et al. Designing, implementing, and evaluating mobile health technologies for managing chronic conditions in older adults: a scoping review. JMIR mHealth and uHealth. 2016;4(2):e29. https://doi.org/10.2196/mhealth.5127.

14. Eldh AC, Ekman I, Ehnfors M. A comparison of the concept of patient participation and patients' descriptions as related to healthcare definitions. Int J Nurs Terminol Classif. 2010;21(1):21-32. https://doi.org/10.1111/j.1744$618 \times .2009 .01141 x$

15. Thórarinsdóttir K, Kristjánsson K. Patients' perspectives on person-centred participation in healthcare: a framework analysis. Nurs Ethics. 2014;21(2): 129-47. https://doi.org/10.1177/0969733013490593.

16. Ekman I, Swedberg K, Taft C, Lindseth A, Norberg A, Brink E, et al. Personcentered care - ready for prime time. Eur J Cardiovasc Nurs. 2011;10(4): 248-51. https://doi.org/10.1016/j.jejcnurse.2011.06.008.

17. Langius-Eklöf A, Christiansen M, Lindström V, Blomberg K, Hälleberg Nyman $M$, Wengström $Y$, et al. Adherence to report and patient perception of an interactive app for managing symptoms during radiotherapy for prostate cancer:descriptive study of logged and interview data. JMIR Cancer. 2017; 3(2):e18. https://doi.org/10.2196/cancer.7599.

18. Gustavell T, Sundberg K, Segersvärd R, Wengström Y, Langius-Eklöf A. Decreased symptom burden following surgery due to support from an interactive app for symptom management for patients with pancreatic and periampullary cancer. Acta Oncol. 2019:1-8. https://doi.org/10.1080/ 0284186X.2019.1633473.

19. Sundberg $K$, Wengström $Y$, Blomberg $K$, Hälleberg-Nyman M, Frank $C$, Langius-Eklöf A. Early detection and management of symptoms using an 
interactive smartphone application (Interaktor) during radiotherapy for prostate cancer. Support Care Cancer. 2017;25(7):2195-204. https://doi.org/ 10.1007/s00520-017-3625-8

20. Algilani S, Langius-Eklöf A, Kihlgren A, Blomberg B. An interactive ICT-platform for early assessment and management of patient-reported concerns among older adults living in ordinary housing -development and feasibility. J Clin Nurs. 2017;26(11-12):1575-83. https://doi.org/10.1111/jocn.13468.

21. Craig P, Dieppe P, Macintyre S, Michie S, Nazareth I, Petticrew M. Developing and evaluating complex interventions: the new Medical Research Council guidance. BMJ. 2008;337:a1655. https://doi.org/10.1136/ bmj.a1655.

22. SFS 2001:453. Socialtjänstlag [Social Services Act] Stockholm: Socialdepartementet; 2001. Available from: http://www.riksdagen.se/sv/ dokument-lagar/dokument/svensk-forfattningssamling/socialtjanstlag-2 001453 sfs-2001-453. Accessed 30 Jan 2018.

23. SFS 1982:763. Hälso- och sjukvårdslag [Health and Medical Services Act] Stockholm: Socialdepartementet; 1982. Available from: http://www. riksdagen.se/sv/dokument-lagar/dokument/svensk-forfattningssamling/ halso\%2D\%2Doch-sjukvardslag-1982763_sfs-1982-763. Accessed 30 Jan 2018.

24. Göransson C, Eriksson I, Ziegert $K$, Wengström $Y$, Langius-Eklöf A, Brovall M, et al. Testing an app for reporting health concerns-experiences from older people and home care nurses. Int J Older People Nursing. 2018;13(2): e12181. https://doi.org/10.1111/opn.12181.

25. Göransson C, Wengström Y, Ziegert K, Langius-Eklöf A, Blomberg K. Self-care ability and sense of security among older persons when using an app as a tool for support. Scand J Caring Sci. 2019;34(3):772-81. https://doi.org/10. $1111 /$ scs.12782.

26. Göransson C, Wengström Y, Ziegert K, Langius-Eklöf A, Eriksson I, Kihlgren A et al. Perspectives of health and self-care among older persons-to be implemented in an interactive information and communication technologyplatform. J Clin Nurs. 2017;26(23-24):4745-55. https://doi.org/10.1111/jocn. 13827.

27. Portenoy RK, Thaler HT, Kornblith AB, Lepore JM, Friedlander-Klar H, Kiyasu $E$, et al. The memorial symptom assessment scale: an instrument for the evaluation of symptom prevalence, characteristics and distress. Eur J Cancer. 1994;30A(9):1326-36. https://doi.org/10.1016/0959-8049(94)90182-1.

28. Browall M, Kenne Sarenmalm E, Nasic S, Wengström Y, Gaston-Johansson F. Validity and reliability of the Swedish version of the memorial symptom assessment scale (MSAS): an instrument for the evaluation of symptom prevalence, characteristics, and distress. J Pain Symptom Manag. 2013;46(1): 131-41. https://doi.org/10.1016/j.jpainsymman.2012.07.023.

29. Vårdguiden, Healthcare online. In English: Health- care- advice- onlineand-on-the phone. Inera; 2017. Available from: https://www.1177.se/ Om-1177/1177--Health-care-advice-online-and-on-the-phone. Accessdate 24 Jan 2017.

30. Vårdguiden 1177. Tema Senior [Theme Senior] (in Swedish); 2017. Available from: https://www.1177.se/Tema/Senior/. Accessed 24 Jan 2017.

31. Eriksson M, Lindström B. Validity of Antonovsky's sense of coherence scale: a systematic review. J Epidemiol Community Health. 2005;59(6):460-6. https:// doi.org/10.1136/jech.2003.018085

32. Langius $A$, Björvell $H$. Coping ability and functional status in a Swedish population sample. Scand J Caring Sci. 1993;7(1):3-10. https://doi.org/10. 1111/j.1471-6712.1993.tb00154.x.

33. Forsberg C, Björvell $H$. Swedish population norms for the GHRI, $H$ I and STAl- state. Qual Life Res. 1993;2(5):349-56. https://doi.org/10.1007/ BF00449430.

34. Nordström G, Nyman CR, Theorell T. Psychosocial adjustment and general state of health in patients with ileal conduit urinary diversion. Scand J Uro Nephrol. 1992;26(2):139-47. https://doi.org/10.1080/00365599.1992. 11690445

35. Söderhamn U, Söderhamn O. Developing and testing the nutritional form for the elderly. Int J Nurs Pract. 2001;7:336-41. https://doi.org/10.1046/j. 1440-172X.2001.00296.X.

36. Söderhamn U, Söderhamn $O$. Reliability and validity of the nutritional form for the elderly (NUFFE). J Adv Nurs. 2002;37(1):28-34. https://doi.org/10. 1046/j.1365-2648.2002.02048.x.

37. Gottfries GG, Noltorp S, Nørgaard N. Experience with a Swedish version of the geriatric depression scale in primary care centres. Int J Geriatr Psychiatry. 1997;12:1029-34. https://doi.org/10.1002/(SICI)1099-1166(199710)12:10\% 3C1029::AID-GPS683\%E3.0.CO;2-D.
38. Wångdahl JM, Mårtensson LI. Measuring health literacy - the Swedish functional health literacy scale. Scand J Caring Sci. 2015;29(1):165-72. https://doi.org/10.1111/scs.12125

39. Mårtensson L, Wångdahl J. S-FHL Scale for functional health literacy Swedish version Guidelines for use of the scale: Uppsala University, University of Gothenburg; 2017 [ver 3:1]. Available from: https://uploads. staticjw.com/ha/halsolitteracitet/guidelines-sfhl-swedish-version-3-1january-2017.pdf. Accessed 31 Oct 2018.

40. Wångdahl JM, Mårtensson LI. The communicative and critical health literacy scale-Swedish version. Scand J Public Health. 2014;42(1):25-31. https://doi. org/10.1177/1403494813500592.

41. Mårtensson L, Wångdahl J. SKKHL-Skala för kommunikativ \& kritisk hälsolitteracitet Svensk version-Handledning för hur du ska använda skalan. Göteborg och Uppsala: Uppsala Universitet \& Göteborg Universitet; 2017 [ver 3:1]. Available from: https://uploads.staticjw.com/ha/halsolitteracitet/ manual-skkhl-skala-version-3-0-januari-2017.pdf. Accessed 31 Oct 2018.

42. Altman DG. Practical statistics for medical research. London: Chapman \& Hall; 1991.

43. Siren A, Knudsen SG. Older adults and emerging digital service delivery: a mixed methods study on information and communications technology use, skills, and attitudes. J Aging Soc Policy. 2017;29(1):35-50. https://doi.org/10. 1080/08959420.2016.1187036.

44. Brink S. Learning in later years in the lifelong learning trajectory. J Intergenerational Relationships. 2017;15(1):14-25. https://doi.org/10.1080/ 15350770.2017.1260391.

45. Mort M, Roberts C, Pols J, Domenech M, Moser I. Ethical implications of home telecare for older people: a framework derived from a multisited participative study. Health Expect. 2015;18(3):438-49. https://doi.org/10. 1111/hex.12109

46. Santoni G, Angleman S, Welmer A-K, Mangialasche F, Marengoni A, Fratiglioni L. Age-related variation in health status after age 60. PLoS One. 2015;10(3):e012077. https://doi.org/10.1371/journal.pone.0120077.

47. Kingston A, Wohland P, Wittenberg R, Robinson L, Brayne C, Matthews FE, et al. Is late-life dependency increasing or not? A comparison of the cognitive function and ageing studies (CFAS). Lancet. 2017;390(10103): 1676-84. https://doi.org/10.1016/S0140-6736(17)31575-1.

48. Steptoe A, Deaton A, Stone AA. Subjective wellbeing, health, and ageing Lancet. 2015;385(9968):640-8. https://doi.org/10.1016/S0140-6736(13)61489-0.

49. Josefsson $\mathrm{K}$, Andersson M, Erikstedt A. Older adults' self-rated health and differences by age and gender: A quantitative study. Healthy Aging Res. 2016;5:1-10. https://doi.org/10.12715/har.2016.5.1.

50. Abdulla A, Adams N, Bone M, Elliot A, Gaffin J, Jones D, et al. Guidance on the management of pain in older people. Age Ageing. 2013;42(SUPP/1):i1i57. https://doi.org/10.1093/ageing/afs200.

51. Vollenbroek-Hutten M, Jansen-Kosterink S, Tabak M, Feletti L, Zia G, N'Dja A, et al. Possibilities of ICT-supported services in the clinical management of older adults. Aging Clin Exp Res. 2017;29(1):49-57. https://doi.org/10.1007/ s40520-016-0711-6.

52. Wolf A, Fors A, Ulin K, Thorn J, Swedberg K, Ekman I. An eHealth diary and symptom-tracking tool combined with person-centered care for improving self-efficacy after a diagnosis of acute coronary syndrome: a substudy of a randomized controlled trial. J Med Internet Res. 2016;18(2):e40. https://doi. org/10.2196/jmir.4890.

53. Quaosar GAA, Hoque MR, Bao YJT. Investigating factors affecting elderly's intention to use m-health services: An empirical study. Telemed E-Health. 2018;24(4):309-14

54. Golomb BA, Chan VT, Evans MA, Koperski S, White HL, Criqui MH. The older the better: are elderly study participants more non-representative? A crosssectional analysis of clinical trial and observational study samples. $\mathrm{Br}$ Med J Open. 2012;6:e000833. https://doi.org/10.1136/bmjopen-2012-000833.

55. Bland M. An introduction to medical statistics. 4th ed. New York: Oxford University Press; 2015.

56. Schulz R, Wahl H-W, Matthews JT. Advancing the aging and technology agenda in gerontology. Gerontologist. 2015;55(5):724-34. https://doi.org/10. 1093/geront/gnu071.

\section{Publisher's Note}

Springer Nature remains neutral with regard to jurisdictional claims in published maps and institutional affiliations. 